\title{
Research
}

\section{Influence of patient payment on antibiotic prescribing in Irish general practice:}

\author{
a cohort study
}

\begin{abstract}
\section{Background}

Antibiotics are widely believed to be overused and misused. Approximately $80 \%$ of all prescriptions for antibiotics are written by GPs. There are many external factors that influence a GP's decision to prescribe, including patient pressure. Access to primary care services operates on a two-tier system in the Republic of Ireland: General Medical Service (GMS) card holders have free access to GPs and medications; and non-card holders (private patients) must pay a non-subsidised fee to visit their GP.
\end{abstract}

\section{Aim}

To ascertain whether there was a difference in antibiotic prescribing practice between those who pay a fee for their GP consultation and those who attend free of charge.

\section{Design and setting}

Cohort study in Irish general practice.

\section{Method}

All GPs attending continuing medical education (CME) groups nationwide were invited to participate from October 2008 until April 2010. GPs gathered data on 100 consecutive consultations including diagnosis and patient characteristics.

\section{Results}

Data were collected from $171 \mathrm{GPs}$ (distributed throughout Ireland), which resulted in 16899 consultations. Antibiotics were prescribed at $3407(20.16 \%)$ consultations. Nearly half of the prescriptions were for GMS card holders $(n=$ $1669 ; 48.99 \%)$ and 1526 (44.79\%) were for private patients; for $212(6.22 \%)$ the payment status of the patient was unknown. Private patients were more likely to receive a prescription for antibiotics lodds ratio 1.23, 95\% confidence interval $=1.14$ to 1.33 .

\section{Conclusion}

These results demonstrate that a GP's decision to provide a prescription for antibiotics may be influenced by whether or not the patient pays for their consultation at the GP interface.

Private patients are more likely than GMS card holders to receive a prescription for antibiotics.

\section{Keywords}

antibacterial agents; fees, medical; genera practice; patient expectation

\section{INTRODUCTION}

The burden of antimicrobial resistance is a major public health concern. ${ }^{1}$ One of the primary factors contributing to resistance is the unnecessary use of antimicrobials, but translating this message into practice is a major obstacle. In a survey commissioned by the European Union, the majority of people believed antibiotics to be effective against viruses and one in five has taken antibiotics to treat 'the flu'.?

Approximately $80 \%$ of antibiotic prescribing is conducted by GPs in the community. ${ }^{3}$ The percentage of antibiotics prescribed unnecessarily is unknown, but it is believed that a number are used to treat minor respiratory tract infections (RTIs). 4 These conditions - such as the common cold, sore throat, acute otitis media and acute bronchitis - are often of viral aetiology and there is no compelling evidence to support the use of antibiotics in their treatment. ${ }^{5-8}$ It has been shown that using antibiotics to treat these conditions does not prevent serious complications in otherwise healthy adults. ${ }^{9}$ The introduction of guidelines alone has not proven to be effective at reducing antibiotic use for conditions that are, mainly, viral. ${ }^{10}$ There is now evidence that those who consume antibiotics are more likely to become infected by organisms resistant to that antibiotic in the weeks and months following their antibiotic course."

There are many external (non-clinical)

M Murphy, MPharm, MPSI, research pharmacist; CP Bradley, BAO, MD, MICGP, FRCGP, professor of general practice, Department of General Practice, School of Medicine; S Byrne, BSc(Hon)Pharmacy, PhD, MPSI, senior lecturer in clinical pharmacy, Pharmaceutical Care Research Group, School of Pharmacy, University College Cork, Cork, Ireland.

Address for correspondence

Colin P Bradley, Department of General Practice, factors that influence a GP's decision to prescribe antibiotics. Patient pressure and time restraints have been quoted as potential reasons for GPs providing treatment, despite clinical evidence suggesting that it is not necessary. ${ }^{12-14}$ GPs perceive the threat of antimicrobial resistance to be less than the marginal benefit of antibiotics, particularly when dealing with patients with whom they are familiar. ${ }^{15}$ Maintaining good relationships is paramount for GPs and they have been shown to overestimate the patient's expectation at a consultation. ${ }^{16}$ The perceived demand by patients for antibiotics has been shown to be associated with GPs decisions to prescribe them. ${ }^{17}$

Considerable variation in practice exists between GPs; those who have been in practice longer have been found to prescribe more antibiotics. ${ }^{18}$ Geographical variation in antibiotic prescribing, which cannot be justified by differences in presentation and demographics, has also been shown to exist in primary care across Europe..$^{19}$ In a study of those who had received antibiotics and those who had not for their symptoms of acute cough, there were also no differences in recovery rates. ${ }^{20}$

The Republic of Ireland is one of three European countries in which antibiotic use in primary care has been increasing - this has occurred at a rate of $3 \%$ per year since $2000 .{ }^{3}$ In the UK and France, considerable reductions in antibiotic prescribing have

2.40 Western Gateway Building, University College Cork, Western Road, Cork, Ireland.

E-mail: c.bradleyqucc.ie

Submitted: 15 February 2011; Editor's response: 28 March 2011; final acceptance: 13 April 2011. (cBritish Journal of General Practice

This is the full-length article (published online 30 August 2011) of an abridged version published in print. Cite this article as: $\mathbf{B r} \mathbf{J}$ Gen Pract 2011; DOI: 10.3399/bjgp11X593820. 


\section{How this fits in}

The remuneration method of GPs is debated in all healthcare systems and GPs are known to respond to incentives. Patient expectation is also known to influence prescribers, particularly for prescriptions for antibiotics. In the Republic of Ireland, only a third of the population have access to their GP free of charge. The young, older people and those who are socioeconomically disadvantaged are overly represented in this group and would be likely to have an increased need for antibiotics. This study offers evidence to suggest that prescribing patterns may be influenced by whether the patient pays for the GP consultation, rather than by clinical need alone.

taken place, mainly due to public awareness campaigns and a reduction in respiratory consultations. ${ }^{21}$

There is considerable debate globally about how primary care services should be funded and delivered. ${ }^{22}$ As a result, policymakers have used a wide variety of strategies to make the best use of national resources. The need for efficient delivery of healthcare services is paramount Currently, in Ireland, access to primary care services operates on a two-tier system:

- General Medical Service (GMS) card holders attend GP surgeries free of charge and are entitled to free medications. Eligibility is means tested and, in $2009,33 \%$ of the population in Ireland were GMS card holders. ${ }^{23}$ GPs are remunerated for the services they provide to GMS patients through a capitation method, whereby the number of visits made by the patient is not regarded. This could be seen as a disincentive for GPs to encourage GMS card holders to re-visit.

- Private patients (non-card holders) must pay a non-subsidised fee to visit their GP. A consumer survey in 2010 found that the average fee per consultation was $€ 51.24$

Almost all GPs in Ireland (96\%) operate a mixture of GMS and private practice lists. ${ }^{25}$

In other countries, such as the UK, GPs working for the NHS are not allowed to charge patients for their family health services. There are many reasons why this regulation was introduced - a GP working in an unregulated private market may have an incentive to provide above the required services, a phenomenon known as 'supplier-induced demand';26 GPs can also be under more pressure from patients to provide unnecessary treatments due to the cost implications for further consultations if required. The method of GP remuneration and patient demands have been acknowledged as some of the main factors that influence the practice of GPs. ${ }^{27}$ In Canada, both salary-based and fee-forservice GPs exist and it was found that there was an association between fee-for-service GPs and high rates of antibiotic prescribing. ${ }^{28} \mathrm{It}$ is postulated that this may affect the GP's decision to prescribe antibiotics during a consultation in Ireland.

\section{METHOD}

\section{Setting}

In 2007, there were 3110 GPs registered in Ireland, but these may not be all practising. ${ }^{29}$ In 2009, 2244 GPs received reimbursement for medical services from the Primary Care Reimbursement Service, which is part of the Health Service Executive. ${ }^{30}$ The majority of GPs in Ireland are regular attendees of the small-group continuing medical education (CME) network; run by the Irish College of General Practitioners, this involves GPs meeting on a regular basis to learn in a mutually supportive group. The system is resourced by 37 CME tutors nationally, has a target population of 1934 GPs, and an attendance of over $80 \%$ of all GPs in Ireland. ${ }^{25}$ Tutors run monthly meetings each year from September until June.

\section{Participants}

All CME tutors and their groups were invited to participate in the study from October 2008 until April 2010. All participating GPs had a mixture of both GMS and private patients in their practice, and each GP completed an anonymous demographic questionnaire detailing their practice size and area, the number of years they had been in practice, and their postgraduate experience.

\section{Data collection}

Participating GPs gathered data on 100 consecutive consultations using a predefined data collection proforma. CME tutors distributed the material at CME meetings and instructions were given to help GPs complete them. Anonymised patient information was recorded including the patient's age, sex, and patient payment status (that is, GMS card holder or private patient). GPs recorded the reason for the consultation or the diagnosis if applicable.

From the information provided, the authors agreed the following were taken to indicate probable RTIs/symptoms: cough 


\section{Table 1. GP characteristics}

\begin{tabular}{lc} 
Characteristic & $\boldsymbol{n}(\%)$ \\
\hline Sex $(n=145)$ & $69(47.59)$ \\
Male & $76(52.41)$ \\
Female & \\
\hline Age, in years $(n=144)$ & $0(0)$ \\
$<30$ & $42(29.17)$ \\
$31-40$ & $52(36.11)$ \\
$41-50$ & $40(27.78)$ \\
$51-60$ & $10(6.94)$ \\
$>61$ & $7(5.22)$ \\
\hline Type of practice $(n=134)$ & $91(67.91)$ \\
Single & $36(26.87)$ \\
Partnership practice $\leq 4$ & \\
Partnership practice $>4$ & $54(37.24)$ \\
Area $(n=145)$ & $36(24.83)$ \\
Urban & $55(37.93)$ \\
Rural & \\
Mixed & $27(28.42)$ \\
\hline Years of practice $(n=95)$ & $34(35.79)$ \\
$<10$ & $28(29.47)$ \\
$11-20$ & $6(6.32)$ \\
$21-30$ & \\
$>31$ & \\
\hline
\end{tabular}

(with/without sputum), chest infection, bronchitis, RTI (lower/upper), sore throat/infection, tonsillitis, pharyngitis, sinusitis, rhinitis, otitis media, otitis externa, earache. A sample (10\%) was doublechecked for coding entry errors.

When an antibiotic was prescribed during the consultation, details of the prescription and directions for use were recorded. If a delayed or deferred prescription for antibiotics was given, which was to be dispensed at a later time if necessary, this was agreed by the GP and patient, and recorded. ${ }^{31}$ Out-of-hours consultations were not recorded.

No data was collected during the summer months as CME groups do not convene during this time. During the time of data collection, eligibility for a GMS card changed; from 1 January 2009, patients aged $>70$ years, who had previously enjoyed automatic entitlement, became subject to a means test.

\section{Analysis}

Data were analysed using Microsoft Office Excel ${ }^{\circledR}$ and Statistical Package for the Social Sciences (version 15.0). Data collected were tested for normality and parametric/nonparametric tests were used as appropriate. Mean and median values were used as appropriate. The Pearson's $\chi^{2}$ tests were performed to compare categorical variables. Student $t$-tests and the MannWhitney U-tests were used to compare numerical variables. Odds ratios (ORs) with corresponding $95 \%$ confidence intervals (Cls) were calculated using logistic regression.

Age-adjusted antibiotic prescription rates were calculated using age-specific rates from the study population and the most recent (2006) national census population data in Ireland; 32 95\% Cls were calculated using the Poisson distribution.

\section{RESULTS}

Data were collected from 171 GPs nationally, who recorded data on 16899 consultations. The mean (standard deviation [SD]) number of consultations recorded per GP was 98.82 (SD 5.37). The majority of GPs who participated completed a demographics questionnaire (145; $84.80 \%$, Table 1). All GPs were from practices with lists of both GMS card holders and private patients. GPs estimated the number of patients that were on their lists. The median total list size was 2400 patients linterquartile range [IQR] 1631-4700), combining the list of GMS card holders (median 900; IQR 500-1425) and the private patient list (median 1500; IQR 1000-2500).

Patient age groups are shown in Figure 1. The median age of GMS patients was 54.0 years (IQR 28.0-73.0 years), while the median age of private patients was 34.0 years (IQR 20.0-49.0 years). The difference in ages was shown to be statistically significant $(z=-32.46, P<0.001, r$ $=0.33)$. A total of $43.20 \%$ of GMS card holders were over the age of 60 years. The majority of those aged 21-60 years were private patients $(4504 ; 64.22 \%)$

\section{Antibiotic prescribing and patient type}

Antibiotics were prescribed at 3407 consultations. The rate of antibiotic prescribing per $100 \mathrm{GP}$ consultations was 20.16 (95\% Cl $=19.51$ to 20.87). Almost half of those prescriptions were for GMS card holders $(1669,48.99 \%)$, while $44.79 \%$ ( $n=$ 1526) were for private patients; the payment status of the recipients of $212(6.22 \%)$ prescriptions was unknown due to missing data. Private patients were more likely than GMS card holders to receive a prescription for antibiotics $\left(\chi^{2}=25.55, P<0.001\right.$, OR 1.23, $95 \% \mathrm{Cl}=1.14$ to 1.33 ). The age-adjusted rate per 100 of the population ${ }^{32}$ receiving prescriptions for antibiotics in both groups was similar: GMS card holders 19.85 (95\% $\mathrm{Cl}=19.81$ to 19.89 ); private patients 22.00 $(95 \% \mathrm{Cl}=21.96$ to 22.05$)$. The highest prescribing rate per 100 consultations was 


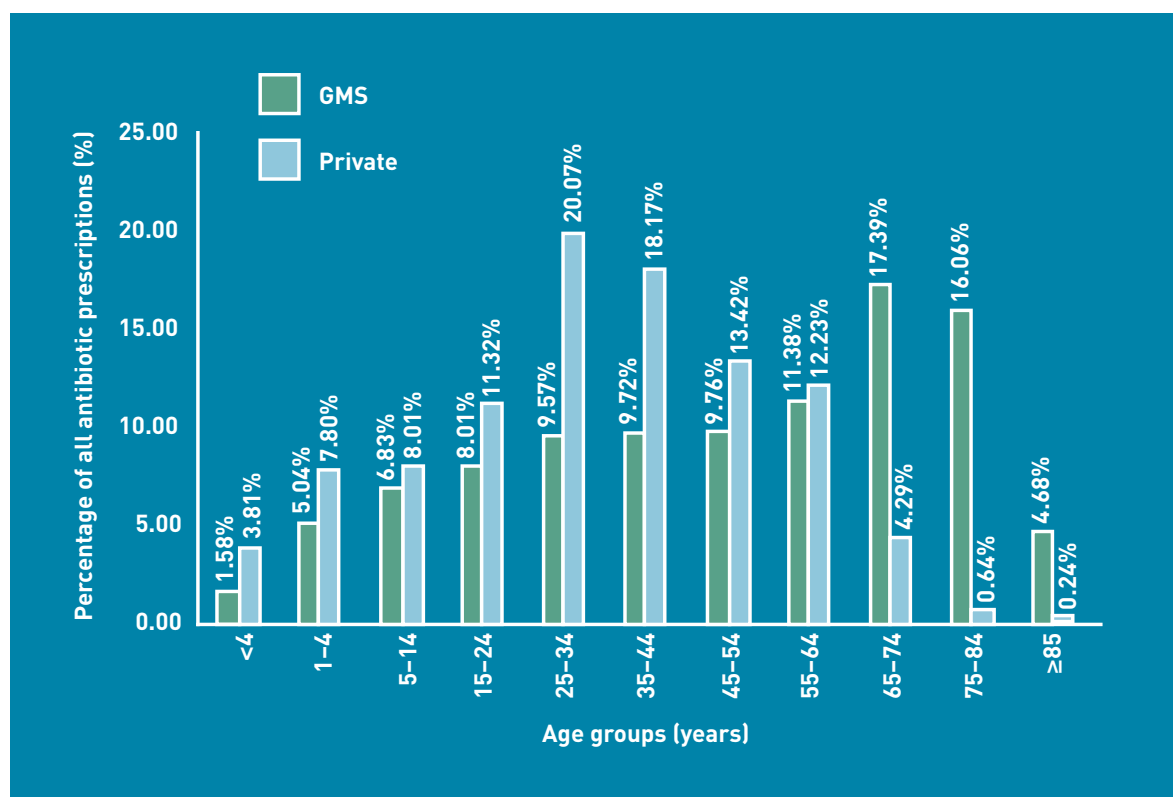

Figure 1. Age profile of General Medical Services card holders and private patient groups.

Figure 2. Comparison of age-specific antibiotic prescription rates in General Medical Services card holders and private patients per 100 consultations.

seen in the 1-4-year-old age group in both GMS card holders (35.67) and private patients (46.46) (Figure 2). The average prescribing rate for patients aged $\geq 65$ years was 16.19 (GMS) and 13.64 (private) per 100 consultations.

Increased age was not shown to be a contributing factor influencing the receipt of prescriptions for antibiotics; people aged $\geq 65$ years were less likely to receive a prescription for antibiotics than patients aged $<65$ years $\left(\chi^{2}=58.12, P<0.001\right.$, OR 0.69 $95 \% \mathrm{Cl}=0.63$ to 0.76 ). When prescribing rates to patients aged $\geq 65$ years were

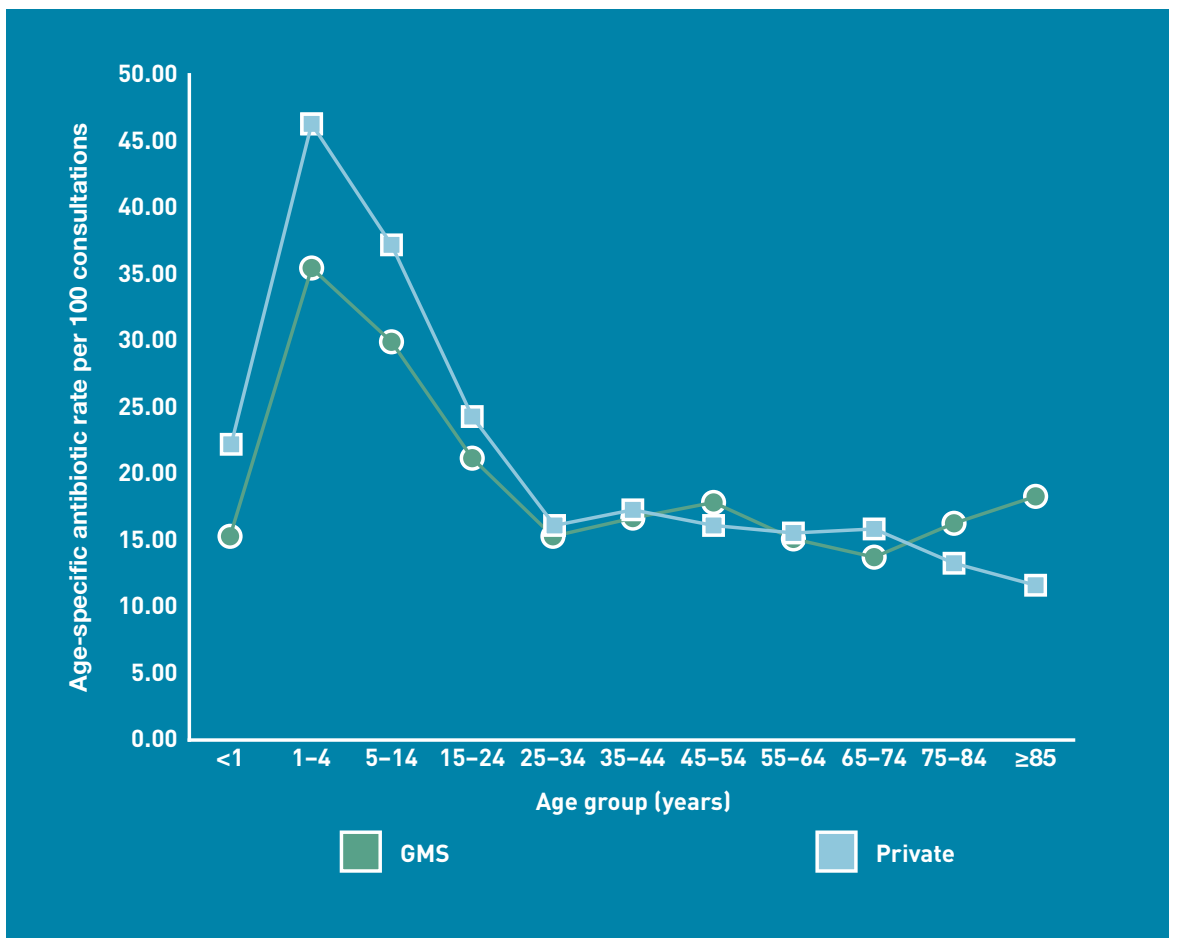

compared with those to adults aged $18-64$ years, those aged $\geq 65$ years were still less likely to receive an antibiotic (OR 0.91, $95 \% \mathrm{Cl}=0.82$ to 1.00 , data not shown): however, this association was not significant $\left(\chi^{2}=3.54, P=0.058\right)$

In total, there were 470 (13.80\%) delayed prescriptions for antibiotics; the patient's GMS status was unknown for 30 (6.38\%) of these, but private patients were more likely to receive a delayed prescription (OR 1.36, $95 \% \mathrm{Cl}=1.14$ to 1.71 ) (Table 2). The majority of antibiotics prescribed for both groups were for diagnosis or symptoms of a respiratory-related illness. A higher percentage of private patients 1 (1037, $67.96 \%$ ) received an antibiotic for a respiratory-related illness compared with GMS card holders (1028, 61.59\%). Private patients were more likely than GMS patients to receive an antibiotic when consulting with a respiratory illness (OR 1.47, 95\% Cl $=1.28$ to 1.69) (Table 2).

\section{DISCUSSION}

\section{Summary}

These results demonstrate that private patients are more likely to receive a prescription for antibiotics, suggesting that whether a patient pays at the GP interface may influence the GP's decision to provide such a prescription. This was not expected as GMS patients are higher users of medical care than private patients due to the higher age demographic and the lower socioeconomic background of the group.

Antibiotic prescribing was particularly high for private patients with respiratory symptoms. In addition, antibiotic prescribing rates for patients aged $\geq 65$ years were not shown to be higher than those for younger patients. Antibiotic use in private patients may also be due to their presenting later and, as they may be charged for a second visit, being hesitant to re-consult if their symptoms worsen. This further supports the theory that non-medical external factors have a role in antibiotic prescribing in primary care. Delayed prescriptions were more likely to be prescribed to private patients, negating the need to re-consult if symptoms deteriorated.

\section{Strengths and limitations}

To the authors' knowledge, this is the first time that information regarding both private patients and GMS card holders has been recorded in the context of antibiotic prescribing. Until this point, it was unknown whether the method of payment influenced the GP's decision to prescribe antibiotics. 
Table 2. Comparison of consultations for private patients and GMS card holders

\begin{tabular}{|c|c|c|c|c|c|}
\hline & Private patients & GMS card holders & $\chi^{2}$ & $P$-value & Odds ratio $(95 \% \mathrm{CI})$ \\
\hline Consultations (any indication), $n$ & 7081 & 9096 & - & - & - \\
\hline Antibiotic prescriptions, $n[\%]$ & 1526 (21.55) & $1669(18.35)$ & 25.55 & $<0.001$ & $1.23(1.14$ to 1.33$)$ \\
\hline $\begin{array}{l}\text { Antibiotic prescriptions for respiratory } \\
\text { symptoms, } n(\%)\end{array}$ & 1037 (68.13) & 1028 (62.04) & 29.03 & $<0.001$ & $1.47(1.28$ to 1.69$)$ \\
\hline Delayed antibiotic prescriptions, $n(\%)$ & $243(15.96)$ & 197 (11.89) & 10.38 & $<0.001$ & $1.36(1.14$ to 1.71$)$ \\
\hline
\end{tabular}

GMS = General Medical Services

A limitation of this study was that GPs did not record the duration of symptoms of each patient, which may influence their decision to prescribe antibiotics. It is generally thought that, on average, private patients wait longer to visit their GP due to the cost implications and are, therefore, likely to have worsening symptoms. GMS card holders do not have the payment barrier to overcome and so may present earlier in their condition; they aso have the opportunity to re-consult at no charge. This will be examined further in qualitative work that is currently being conducted.

Another issue is the fact that age-specific profiles of GP panels are unavailable in Ireland. Patients do not have to be registered with a particular GP and are, therefore, free to visit any doctor. This makes it difficult for GPs to keep a valid register of their patients. It is also difficult to compare GPs using prescribing tools, such the standardised prescribing ratio, as their panel lists are not available. ${ }^{33}$

The most recent general practice-based morbidity survey in the UK identified 'symptoms, signs and ill-defined conditions' as one of the most common computercoded group of disorders. ${ }^{34}$ Diagnostic codes were not used in this study as a large proportion of consultations that take place in general practice cannot be given a definite diagnostic label.

Participating GPs were aware that information on their antibiotic prescribing was to be used to feed back to their CME groups; however, they were unaware that the payment method of the patient would be the subject of a subsequent analysis. The population of GPs in this study may be skewed towards those with an interest in the area of antibiotic prescribing but their behaviour might be expected to be less influenced by non-clinical factors, such as payment method of the patient.

\section{Comparison with existing literature}

GMS card holders are known to be higher consumers of medical care; they had an average of six visits per year in 2001, compared with 2.3 visits for those without a medical card. ${ }^{35}$ GMS card holders represent an older population demographic pattern, as seen in this study in which over $40 \%$ of patients were $>60$ years. Eligibility for GMS cards is means tested and the majority of patients have a lower socioeconomic status than the general population. Research to date on antibiotic prescribing in Ireland has not included non-GMS card holders. ${ }^{36}$ Pharmacy sales data is available but holds no information on individuals. ${ }^{37}$ Unlike other countries, in Ireland information on diagnostic indications associated with prescriptions for antibiotics in the community is not known. ${ }^{3}$ This data is vital if strategies are to be developed to reduce antibiotic use and identify where potential overprescribing is occurring. ${ }^{38}$

Older patients are more likely to develop complications such as pneumonia, following a respiratory infection ${ }^{9}$ and, therefore, antibiotic use in this cohort would be expected to be higher than in the general population. However, this study found that older patients were no more likely to receive an antibiotic than patients aged $<65$ years. This may indicate that inappropriate prescribing is occurring more in the younger, healthier population. This study showed that, in Ireland, the average rate of antibiotic use in the older cohort is lower than in the general population; this is contrary to other countries such as the UK and the Netherlands, where the highest antibiotic rates are seen in older people (that is, those aged $>75$ years). ${ }^{39}$ It is acknowledged, however, that this study was conducted in general practices and, as such, did not include prescription data for patients in long-stay care facilities where antibiotics are often prescribed.

High antibiotic rates were seen in the 1-4-year-old age group for both GMS card holders and private patients, with nearly one in two private consultations in this age group resulting in a prescription for antibiotics lage-specific antibiotic rate: 46.46 per 100 consultations). Members of this age group are commonly the highest 
consumers of antibiotics. 38,39

The proportion of delayed antibiotic prescriptions that are dispensed is unknown. This study found that delayed prescriptions accounted for $13.80 \%$ of the total number of prescriptions written. Currently, in Ireland, as patients are free to visit any pharmacy to dispense their medication, there is no procedure for follow-up to determine whether delayed prescriptions are dispensed or not; as such, the doctor has no way of knowing whether the prescription is taken by the patient, unless that patient provides this information at their next GP visit. This study found that delayed prescriptions were more likely to be given to private patients, negating their need to re-consult at an additional charge. This may indicate that diagnostic uncertainty has a significant role in antibiotic prescribing decisions in primary care. ${ }^{40}$ The option of advising patients to re-consult if their condition deteriorates is more difficult with private patients as there are cost implications. This alone may place more pressure on the GP to prescribe as, despite their advice, they may not see the patient again. This could be a significant factor as to why private patients are more likely to receive an antibiotic for delayed use.

Wide variation in antibiotic prescribing is known to exist in primary care and differences in health systems have been suggested as one reason why this is occurring. Patient pressure has been quoted as a factor in unnecessary antibiotic prescribing, particularly with regard to respiratory conditions. Research has also shown that GPs are more likely to provide a prescription if they believe that the patient wants one. 13,41 It would appear in Ireland that this factor is pertinent as the issue of patient payment at the point of the consultation exists. A study comparing the effect of a GP charge in Northern Ireland (where access to GPs is free) and the Republic of Ireland, found that a quarter of private patients had not gone to their GP with a medical problem in the previous year due to the cost. ${ }^{42}$ This would suggest that GPs may feel more compelled to provide services that they think are expected by their private patients because they have paid for the consultation; GPs may also believe that patients will not return if their expectations are not met.

Antibiotic prescribing has also been shown to encourage subsequent attendance for patients who experience similar symptoms in the future. ${ }^{43}$ The current study suggests that, although patient pressure for antibiotics could occur with all patients, it could be a particular issue with private patients. These are a younger, healthier cohort than GMS card holders and, yet, the likelihood of receiving a prescription for antibiotics is greater.

\section{Implications for research}

Patients should have the right to the same treatment regardless of whether they pay for the service provided by their GP; this study questions this equity, particularly given that GMS patients in Ireland are higher utilisers of medical care than the general population. However, with respect to GP visits, it is possible that patients will behave differently when a charge is involved and that private patients may wait longer than GMS card holders before consulting.

Further exploration of the influence that payment methods have on prescribing ought to involve cases that are matched for severity. In addition, other countries should be aware of the possible influence that reimbursement structures in general practice may have on the prudence with which antibiotics are prescribed.

obtained from all GPs by participation in the study.

\section{Provenance}

Freely submitted; externally peer reviewed.

\section{Competing interests}

The authors have declared no competing interests.

\section{Acknowledgements}

The authors would like to thank the GPs and the CME groups who participated in the study.

\section{Discuss this article}

Contribute and read comments about this article on the Discussion Forum: http://www.rcgp.org.uk/bjgp-discuss 


\section{REFERENCES}

1. World Health Organisation. Global strategy for containment of antimicrobial resistance. Geneva: WHO, 2001.

2. Special Eurobarometer 338. Antimicrobial Resistance. Belgium: TNS Opinion \& Social, 2010.

3. Cunney R. Strategy for the Control of Antimicrobial Resistance in Ireland (SARI). Dublin: National Disease Surveillance Centre, 2001.

4. Muller A, Coenen S, Monnet DL. European Surveillance of Antimicrobial Consumption (ESAC): outpatient antibiotic use in Europe, 1998-2005. Euro Surveill 2007; 12(10): E071011.1.

5. Del Mar CB, Glasziou PP, Spinks AB. Antibiotics for sore throat. Cochrane Database Syst Rev 2006; (4): CD000023.

6. Glasziou PP, Del Mar CB, Sanders SL, Hayem M. Antibiotics for acute otitis media in children. Cochrane Database Syst Rev 2004; (1): CD000219.

7. Smucny J, Fahey T, Becker L, et al. Antibiotics for acute bronchitis. Cochrane Database Syst Rev 2000; (4): CD000245.

8. Arroll B, Kenealy T. Antibiotics for the common cold. Cochrane Database Syst Rev 2000; (2): CD000247.

9. Petersen I, Johnson AM, Islam A, et al. Protective effect of antibiotics against serious complications of common respiratory tract infections: retrospective cohort study with the UK General Practice Research Database. BMJ 2007; 335(7627): 982

10. Rautakorpi UM, Huikko S, Honkanen P, et al. The Antimicrobial Treatment Strategies (MIKSTRA) program: a 5-year follow-up of infection-specific antibiotic use in primary health care and the effect of implementation of treatment guidelines. Clin Infect Dis 2006; 42(9): 1221-1230.

11. Costelloe $C$, Metcalfe $C$, Lovering $A$, et al. Effect of antibiotic prescribing in primary care on antimicrobial resistance in individual patients: systematic review and meta-analysis. BMJ 2010; 340: c2096.

12. Little $P$, Dorward $M$, Warner $G$, et al. Importance of patient pressure and perceived pressure and perceived medical need for investigations, referral, and prescribing in primary care: nested observational study. BMJ 2004; 328(7437): 444.

13. Macfarlane J, Holmes W, Macfarlane R, Britten N. Influence of patients expectations on antibiotic management of acute lower respiratory tract illness in general practice: questionnaire study. BMJ 1997; 315(7117): 1211-1214.

14. Cotter M, Daly L. Antibiotic prescription practices of general practitioners. Ir Med J 2007; 100(9): 598-601

15. Butler CC, Rollnick S, Pill R, et al. Understanding the culture of prescribing: qualitative study of general practitioners' and patients' perceptions of antibiotics for sore throats. BMJ 1998; 317(7159): 637-642.

16. Mangione-Smith R, McGlynn EA, Elliott MN, et al. The relationship between perceived parental expectations and pediatrician antimicrobial prescribing behavior. Pediatrics 1999; 103(4 Pt 1): 711-718.

17. Coenen S, Michiels B, Renard D, et al. Antibiotic prescribing for acute cough: the effect of perceived patient demand. Br J Gen Pract 2006; 56(524): $183-190$

18. Akkerman AE, Kuyvenhoven MM, van der Wouden JC, Verheii TJ. Prescribing antibiotics for respiratory tract infections by GPs: management and prescriber characteristics. Br J Gen Pract 2005; 55(511): 114-118.

19. Ferech M, Coenen S, Malhotra-Kumar S, et al. European Surveillance of Antimicrobial Consumption (ESAC): outpatient antibiotic use in Europe. $J$ Antimicrob Chemother 2006; 58(2): 401-407.

20. Butler CC, Hood K, Verheij T, et al. Variation in antibiotic prescribing and its impact on recovery in patients with acute cough in primary care: prospective study in 13 countries. BMJ 2009; 338: b2242.

21. Ashworth M, Charlton J, Ballard K, et al. Variations in antibiotic prescribing and consultation rates for acute respiratory infection in UK general practices 1995-2000. Br J Gen Pract 2005; 55(517): 603-608.

22. Belien P. Healthcare systems. A new European model? Pharmacoeconomics 2000; 18 (Suppl 1): 85-93.

23. Health Service Executive (HSE). Annual Report and Financial Statements 2009. County Kildare: HSE, 2009.

24. National Consumer Agency. Doctors and dentists survey. Dublin, Ireland: National Consumer Agency, 2010

25. O'Dowd T, O'Kelly F, O'Kelly M. Structure of general practice in Ireland 1982-2005. Dublin: Trinity College and Irish College of General Practice, 2006.

26. Greenberg W. Competition, regulation, and rationing in health care. Michigan: Health Administration Press, 1991.

27. Geneau R, Lehoux P, Pineault R, Lamarche P. Understanding the work of general practitioners: a social science perspective on the context of medical decision making in primary care. BMC Fam Pract 2008; 9: 12.

28. Hutchinson JM, Foley RN. Method of physician remuneration and rates of antibiotic prescription. CMAJ 1999; 160(7): 1013-1017

29. WHO. Health For All-DataBase (HFA-DB). Number of general practitioners, 2009. Denmark: World Health Organisation, 2009

30. Health Service Exceutive Primary Care Reimbursement Service. Payments to general practitioners 2009. Dublin, Ireland: Health Service Executive Primary Care Reimbursement Service, 2010

31. Spurling GK, Del Mar CB, Dooley L, Foxlee R. Delayed antibiotics for respiratory infections. Cochrane Database Syst Rev 2007; (3): CD004417

32. Central Statistics Office. Census 2006 Volume 2-Ages \& Marital status. Dublin: Central Statistics Office, 2007.

33. Johnson Z, Hayes C, Dack P. The standardized prescribing ratio - a new method for comparing prescribing between GPs, controlling for patient age and sex. Pharmacoepidemiol Drug Saf 1997; 6(5): 337-345.

34. Fleming DM, Cross KW, Barley MA. Recent changes in the prevalence of diseases presenting for health care. Br J Gen Pract 2005; 55(517): 589-595.

35. Layte R, Nolan A, Nolan B. Poor prescriptions-poverty and access to community heath services. Dublin, Ireland: Combat Poverty Agency, 2007.

36. McGowan B, Bergin C, Bennett K, Barry M. Utilisation of antibiotic therapy in community practice. Ir Med J 2008; 101(9): 273-276.

37. Oza A, Cunney R. Outpatient antibiotic use in Ireland in the first half of 2009. Dublin, Ireland: Disease Surveillance Report of HPSC. Epi-Insight 2009; 10(11): $1-3$

38. Akkerman AE, van der Wouden JC, Kuyvenhoven MM, et al. Antibiotic prescribing for respiratory tract infections in Dutch primary care in relation to patient age and clinical entities. J Antimicrob Chemother 2004; 54(6): 1116-1121.

39. Majeed A, Moser K. Age- and sex-specific antibiotic prescribing patterns in general practice in England and Wales in 1996. Br J Gen Pract 1999; 49(446): 735-736.

40. Hopstaken RM, Stobberingh EE, Knottnerus JA, et al. Clinical items not helpful in differentiating viral from bacterial lower respiratory tract infections in general practice. J Clin Epidemiol 2005; 58(2): 175-183.

41. Britten $N$, Ukoumunne 0 . The influence of patients' hopes of receiving a prescription on doctors' perceptions and the decision to prescribe: a questionnaire survey. BMJ 1997; 315(7121): 1506-1510.

42. O'Reilly D, O'Dowd T, Galway KJ, et al. Consultation charges in Ireland deter a large proportion of patients from seeing the GP: Results of a cross-sectional survey. Eur J Gen Pract 2007; 13(4): 231-236.

43. Little P, Gould C, Williamson I, et al. Reattendance and complications in a randomised trial of prescribing strategies for sore throat: the medicalising effect of prescribing antibiotics. BMJ 1997; 315(7104): 350-352. 